


\section{Pulmonary Complications of HIV}

Edited by

Charles Feldman, Eva Polverino and

Julio A. Ramirez

\section{Editor in Chief \\ Tobias Welte}

This book is one in a series of ERS Monographs. Each individual issue provides a comprehensive overview of one specific clinical area of respiratory health, communicating information about the most advanced techniques and systems required for its investigation. It provides factual and useful scientific detail, drawing on specific case studies and looking into the diagnosis and management of individual patients. Previously published titles in this series are listed at the back of this Monograph.

ERS Monographs are available online at www.erspublications.com and print copies are available from www.ersbookshop.com

Purchased by ,

From: European Respiratory Society Publications (reader.ersjournals.com) 
Continuing medical education (CME) credits are available through many issues of the ERS Monograph. Following evaluation, successful Monographs are accredited by the European Board for Accreditation in Pneumology (EBAP) for 5 CME credits. To earn CME credits, read the book of your choice (it is clearly indicated on the online table of contents whether CME credits are available) then complete the CME question form that is available at www.erseducation.org/e-learning/cme-tests.aspx

Editorial Board: Andrew Bush (London, UK), Peter Calverley (Liverpool, UK), Martin Kolb (Hamilton, ON, Canada), Kjell Larsson (Stockholm, Sweden)

Managing Editor: Rachel White

European Respiratory Society, 442 Glossop Road, Sheffield, S10 2PX, UK

Tel: 441142672860 | E-mail: Monographdersj.org.uk

Published by European Respiratory Society @2014

December 2014

Print ISBN: 978-1-84984-054-5

Online ISBN: 978-1-84984-055-2

Print ISSN: $2312-508 \mathrm{X}$

Online ISSN: 2312-5098

Printed by Page Bros Ltd, Norwich, UK

All material is copyright to European Respiratory Society. It may not be reproduced in any way including electronic means without the express permission of the company.

Statements in the volume reflect the views of the authors, and not necessarily those of the European Respiratory Society, editors or publishers.

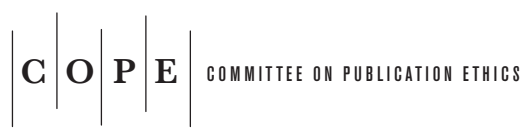

This journal is a member of and subscribes to the principles of the Committee on Publication Ethics.
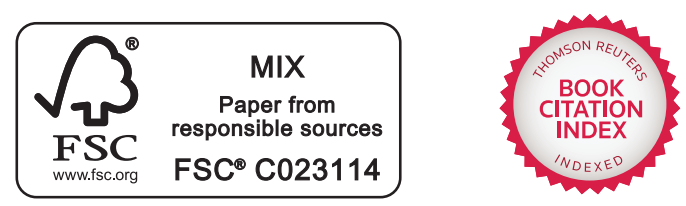

Purchased by , 


\section{Contents}

Pulmonary Complications of HIV

Preface

Guest Editors

Introduction

List of abbreviations

1. The global epidemiology of HIV Willem Daniel Francois Venter

2. Current antiretroviral therapy Alex P. Salam and Anton L. Pozniak

3. Pulmonary immunity Martin Gnoni and Julio A. Ramirez

4. Vaccines

Christian Manzardo, Agathe Leon, Pedro Castro, Guillermo Mena, Felipe García and José M. Miró

5. Lung transplantation

Hendrik Suhling, Mark Greer and Jens Gottlieb

6. HIV in pregnancy: diagnostic and therapeutic implications for the newborn

Mark Fredric Cotton, Stuart Maxwell Kroon and Helena Rabie

7. A paediatric perspective

Robin J. Green, Adéle Pentz, Jessica Kolberg and Refiloe Masekela

8. Bacterial community-acquired pneumonia Charles Feldman and Ronald Anderson

9. Tuberculosis Giovanni Sotgiu, James Brown, Marc Lipman, Andrea Piana, Alberto Matteelli, Rosella Centis, Stefano Aliberti and Giovanni Battista Migliori

10. Nontuberculous mycobacterial pulmonary infections Paula Peyrani and Julio A. Ramirez

vii

ix

xii

xiii

1

Purchased by,

From: European Respiratory Society Publications (reader.ersjournals.com)
Number 66

December 2014 
11. Pneumocystis jirovecii infection

Meghan Fitzpatrick and Alison Morris

12. Viral infections

Catia Cillóniz, Maria Angeles Marcos, Antoni Torres and Eva Polverino

13. Other fungal and protozoan infections

Gerrit Ahrenstorf and Matthias Stoll

14. Pulmonary malignancies Jean-Paul Sculier, Nathalie Meuleman, Anne-Pascale Meert and Thierry Berghmans

15. Chronic obstructive lung diseases

Engi F. Attia and Kristina Crothers

16. Interstitial lung disease

Rodrigo Cavallazzi and Jesse Roman

17. Pulmonary arterial hypertension

Olivier Sitbon, Laurent Savale, Caroline Sattler, Xavier Jaïs, David Montani,

Marc Humbert and Gérald Simonneau

18. Bronchiectasis

Montserrat Vendrell, Gerard Muñoz and Javier de Gracia

19. Immune reconstitution inflammatory syndrome

David M. Murdoch

Purchased by ,

From: European Respiratory Society Publications (reader.ersjournals.com) 


\title{
Preface
}

\author{
Tobias Welte, Editor in Chief
}

According to figures from UNAIDS, there were 34.2 million people living with HIV in 2011, a rise of 5.1 million on 2001. Of these, 2.5 million had become newly infected, a reduction of $22 \%$ on figures from 2001. 1.7 million people died from AIDS-related causes in 2011, a decline of $11 \%$ on the number of AIDS-related deaths in 2001. A similar decrease in new infections was seen amongst neonates and infants: from 570000 in 2003 (when figures peaked) to 330000 in 2011. However, it must be acknowledged that these are global figures and they hide a wide diversity in the number of cases and deaths between countries and risk groups. The most affected continent continues to be subSaharan Africa, followed by Eastern Europe and the Caribbean, and the following groups are disproportionately affected: men who have sex with men, female sex workers, injecting drug users, truck drivers, fishermen and the military [1].

Tremendous progress has been made during the last decade, not only in preventive measures but also in HIV treatment. 25 antiretroviral drugs have been licensed for HIV treatment and, thanks to international financial aid and a reduction in the price, these drugs are now available in low- and middle-income countries. More than 8 million individuals are now on therapy in low- and middle-income countries, and as a result, the death rate in some of the hardest hit countries has started to decline, following mortality reductions in the USA and Europe in the late nineties. The life expectancy of an HIV-infected individual who is receiving treatment is approaching that of an uninfected individual, although there are side-effects of the treatment that have an influence on quality of life and the ability to work and participate normally in daily life [2].

That said, progress in the treatment of AIDS has led to carelessness, especially in western capitals. Important precautions are being forgotten and a rise in new infections has been observed during recent years.

Pulmonary manifestations represent one of the major AIDS complications and are the most life-threatening amongst those 
with AIDS. In parallel to the progress in HIV treatment in general, new diagnostic and therapeutic possibilities have recently been developed for various HIV-associated pulmonary complications. This issue of the ERS Monograph summarises the current practices and new developments in the prevention, diagnosis and treatment of HIV-related pulmonary complications. I want to congratulate Charles Feldman, Eva Polverino and Julio Ramirez on the tremendous work they have done in compiling this excellent Monograph. This book should be of interest to everybody involved in HIV management worldwide. I hope it will stimulate joint research for a better understanding of and more successful therapy for HIV-related pulmonary infectious diseases.

\section{References}

1. Piot P, Quinn TC. Response to the AIDS pandemic - a global health model. N Engl J Med 2013; 368: $2210-2218$.

2. Mills EJ, Barnighausen T, Negin J. HIV and aging - preparing for the challenges ahead. N Engl J Med 2012; 366: $1270-1273$.

Pưrchased by ,

From: European Respiratory Society Publications (reader.ersjournals.com) 


\title{
Guest Editors
}

\author{
Charles Feldman
}

Charles Feldman is currently the Professor of Pulmonology, Chief Physician, and Head of the Pulmonology Division at the Department of Internal Medicine, Charlotte Maxeke Johannesburg Academic Hospital and University of the Witwatersrand (Johannesburg, South Africa).

He received his undergraduate degree ( $\mathrm{MB} B \mathrm{Ch}$ ) from the University of the Witwatersrand in 1975. Following his internship at Johannesburg Hospital, he specialised in internal medicine, receiving his FCP (SA) in 1981. In 1993 he was registered as a pulmonologist. He was awarded his FRCP (UK) in 1997. His

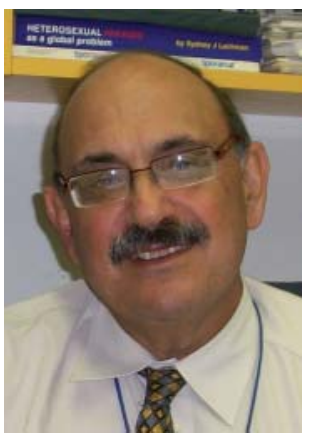
additional postgraduate degrees included a $\mathrm{PhD}$ (1991) and a DSc (2009) from the University of the Witwatersrand, both of these on the basis of a thesis in the field of CAP.

Charles Feldman has been active in both national and international societies. He has been President of the South African Thoracic Society (SATS) on two previous occasions, and is currently a member of the Executive Committee of the Federation of Infectious Diseases Societies of Southern Africa (FIDSSA), a federation that represents all of the individual infectious disease societies in South Africa. He is also Editor-in-Chief of the Federation's Journal, the Southern African Journal of Infectious Diseases. Internationally, Charles Feldman has acted as the national delegate for South Africa for the European Respiratory Society (ERS), and in 2014 he was made a Foundation Fellow of the ERS in recognition of his sustained research in the field of respiratory diseases. He is also an active member of the American College of Chest Physicians (ACCP) and the American Thoracic Society (ATS).

Charles Feldman's research is translational and his interest is primarily in the field of CAP, particularly pneumococcal pneumonia, especially in the setting of HIV infection. His basic research has focused on the interactions between the various factors that play a role in the pathogenesis and outcome of pneumococcal infections, namely, the microorganism and its virulence factors, the various host defence mechanisms, and the 
commonly used antimicrobial agents. As part of his clinical research, Charles Feldman has contributed to various multicentre international collaborative studies investigating multiple aspects of CAP.

Charles Feldman's research has been published more than 300 times, as books, book chapters, articles and abstracts. He has presented at more than 300 congresses, almost half of them international.

\section{Eva Polverino}

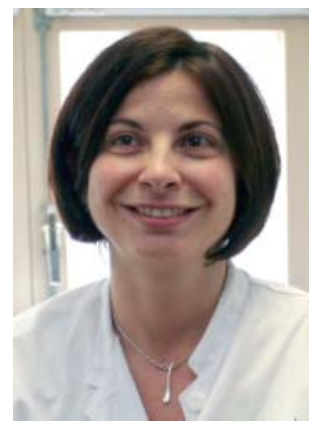

Eva Polverino is an expert in respiratory infections and is Senior Investigator at the Hospital Clinic of Barcelona (IDIBAPS, University of Barcelona, Barcelona, Spain) and Associate Professor at the University of Barcelona.

She graduated in Medicine at the University of Naples (Naples, Italy) and went on to specialise in pulmonology at the University of Pisa (Pisa, Italy). After a training period at the Hospital Clinic of Barcelona focusing on gas exchange, she gained a $\mathrm{PhD}$ in cardiopulmonary pathophysiology at the University of Pisa. In 2007 she moved to the Department of Pulmonology at the Hospital Clinic of Barcelona, working in the field of respiratory infections.

Eva Polverino is an active member of several respiratory societies: the European Respiratory Society (ERS), the American Thoracic Society (ATS), the Sociedad Española de Neumología y Cirugía Torácica (SEPAR), and the Catalan Society of Pulmonology (SOCAP). She is currently Chair of the ERS Respiratory Infections Group, Co-Chair and member of the Steering Committee of the European Registry and Clinical Research Collaborarion in Bronchiectasis (EMBARC), and Chair of the European task force on adult non-CF bronchiectasis (ERS 2014).

Eva Polverino has been an oral session facilitator and speaker at many European, American, Latin-American and Italian respiratory congresses. She has presented more than 150 oral communications at scientific congresses/courses and more than 200 communications (abstracts, posters, etc.).

Eva Polverino's personal research interests focus on respiratory infections and particularly CAP, healthcare-associated CAP, cystic fibrosis and non-cystic fibrosis bronchiectasis, and humoral immunodeficiencies, with particular attention to epidemiology, risk factors, outcome, treatment and prevention of the most relevant respiratory infections. 


\section{Julio A. Ramirez}

Julio A. Ramirez is the Chief of the Division of Infectious Diseases, Professor of Medicine and the Director of the Infectious Diseases Fellowship Training Program at the University of Louisville School of Medicine (Louisville, KY, USA).

He received his medical degree and internal medicine training at La Plata National University School of Medical Science (La Plata, Argentina). He went on to complete: a fellowship in critical care medicine at the National Institute of Respiratory Diseases and Thoracic Surgery at the University of Chile (Santiago, Chile); a residency in internal medicine at the Lincoln Medical Center, New York Medical College (New York, NY, USA); and a fellowship in infectious diseases at the University of Louisville School of Medicine. He is board certified in internal medicine and holds a subspecialty certification in infectious diseases.

Julio Ramirez's research interests include clinical research in the field of pneumonia, and basic research in the field of diagnosis and pathogenesis of infections due to atypical pathogens. He has more than 100 publications in these areas, in journals such as Annals of Internal Medicine, Archives of Internal Medicine, Clinical Infectious Diseases and Chest. He is also a reviewer for several journals including the New England Journal of Medicine and Annals of Internal Medicine.

Julio Ramirez has served as a member of the American Thoracic Society (ATS) committee for the development of national guidelines for the management of CAP, and has served as a member of the Food and Drug Administration advisory committee for anti-infective drugs. He is also a Fellow in the American College of Physicians (ACCP). 


\title{
Introduction
}

\author{
Charles Feldman ${ }^{1}$, Eva Polverino ${ }^{2}$ and Julio A. Ramirez ${ }^{3}$
}

Despite significant advances in the overall management of patients, including the use of various preventative strategies, chemoprophylaxis and ART, the burden of disease worldwide that is due to HIV infection remains high, particularly in low-income countries. The major impact of HIV infection falls on the respiratory system, with the spectrum of conditions that complicate HIV infection spanning a myriad of respiratory conditions. These include both infectious diseases (particularly TB, CAP, PCP and various other opportunistic infections) and noninfectious diseases (such as COPD and asthma, bronchiectasis, lung cancer, diffuse parenchymal lung disorders and pulmonary vascular disorders).

While ART has had a very positive impact on the management of HIV infection, patients still continue to develop complications that are related to HIV infection, many of which are linked with lifestyle, such as ongoing smoking, alcohol consumption and drug use. The introduction of ART itself may occasionally be associated with the development of respiratory and systemic manifestations as a consequence of IRIS.

It is therefore with delight that we introduce this Monograph, which comprehensively addresses the very numerous and diverse conditions that may be associated with and complicate HIV infection. The chapters span the spectrum of infectious and noninfectious diseases, and address issues both in paediatric and adult populations. Each of the 19 chapters is written by acknowledged experts in the field and provides a comprehensive description of the conditions associated with HIV infection. The authors provide state-of-the-art updates on the different areas discussed, and many chapters include recommendations for the management of the various conditions. Topics discussed include: the epidemiology of HIV infection; current antiretroviral recommendations; communicable and non-communicable diseases and their treatment and prevention; HIV infection in pregnancy, and the diagnostic and therapeutic implications for the newborn; complications in paediatric practice; transplantation; and IRIS in patients on ART.

It is becoming increasingly common for physicians to encounter patients with HIV infection in their daily practice, and it is hoped that this Monograph will provide an interesting and informative insight into the various complications that may occur in these patients.

\footnotetext{
${ }^{1}$ Division of Pulmonology, Dept of Internal Medicine, Charlotte Maxeke Johannesburg Academic Hospital and Faculty of Health Sciences, University of Witwatersrand, Johannesburg, South Africa. ${ }^{2}$ Dept of Pneumology, Institut Clinic del Tórax, Hospital Clinic of Barcelona Institut d'Investigacions Biomèdiques August Pi i Sunyer (IDIBAPS), University of Barcelona (UB) - SGR 911 - Ciber de Enfermedades Respiratorias (Ciberes), Barcelona, Spain. ${ }^{3}$ Division of Infectious Diseases, School of Medicine, University of Louisville, Louisville, KY, USA. 


\section{List of abbreviations}

$\begin{array}{ll}\text { ART } & \text { Antiretroviral therapy } \\ \text { BCG } & \text { Bacille Calmette-Guerin } \\ \text { CAP } & \text { Community-acquired pneumonia } \\ \text { CART } & \text { Combination antiretroviral therapy } \\ \text { CMV } & \text { Cytomegalovirus } \\ \text { COPD } & \text { Chronic obstructive pulmonary disease } \\ \text { EBV } & \text { Epstein-Barr virus } \\ \text { FEV1 } & \text { Forced expiratory volume in 1 s } \\ \text { FVC } & \text { Forced vital capacity } \\ \text { HAV } & \text { Hepatitis A virus } \\ \text { HBV } & \text { Hepatitis B virus } \\ \text { HCV } & \text { Hepatitis C virus } \\ \text { HLA } & \text { Human leukocyte antigen } \\ \text { IFN } & \text { Interferon } \\ \text { IL } & \text { Interleukin } \\ \text { IRIS } & \text { Immune reconstitution inflammatory syndrome } \\ \text { LIP } & \text { Lymphocytic interstitial pneumonia } \\ \text { LRTI } & \text { Lower respiratory tract infection } \\ \text { NNRTI } & \text { Non-nucleoside reverse transcriptase inhibitor } \\ \text { NRTI } & \text { Nucleoside reverse transcriptase inhibitor } \\ \text { PAH } & \text { Pulmonary arterial hypertension } \\ \text { PCP } & \text { Pneumocystis jirovecii pneumonia } \\ \text { PCV } & \text { Pneumococcal conjugate vaccine } \\ \text { PH } & \text { Pulmonary hypertension } \\ \text { PPV } & \text { Pneumococcal polysaccharide vaccine } \\ \text { ROS } & \text { Reactive oxygen species } \\ \text { RSV } & \text { Respiratory syncytial virus } \\ \text { TB } & \text { Tuberculosis } \\ \text { TMP-SMX } & \text { Trimethoprim-sulfamethoxazole } \\ \text { TNF } & \text { Tumour necrosis factor } \\ & \end{array}$

Purchased by ,

From: European Respiratory Society Publications (reader.ersjournals.com) 